\title{
OPERATING ISSUE NETWORKS ON THE WEB
}

\author{
RICHARD ROGERS
}

\section{INTRODUCTION}

Arguably, a small segment of organizations, governments and corporations have moved beyond 'using' to 'operating' the Internet. One of the beginnings of 'Net operation' lay in the emergence of Internet intelligence and monitoring companies. In 1995 the first of these companies was viewed in light of its ready off-Web comparison, the news-clipping service. Gradually, however, the companies have become known as Internet 'surveillance' firms, where the main services comprise actively 'monitoring' what's being said on the Net by their competitors (on competitor websites), by their critics (on 'rogue' and other websites), and by 'Chinese whisperers' (on newsgroups, mailing lists and listservs) (New York Times, 8 March 1999). To their clients the monitoring companies send indices, largely in the well-known styles of Web and newsgroup search engine returns. Depending on the severity of the 'word on the Net', the surveillance companies also recommend some form of action to be taken, in order to quash the rumour or put a more permanent end to the mongering (see Figure 1).

While much of the more serious recommended action appears to be of the legal variety, in the form of trademark infringement, unfair trade and/or liable law suits, ${ }^{1}$ the less severe falls into the realm of 'media tactics'. Indeed, certain corporations under fire for their human rights and environmental records often engage in tactical Net media (Garcia and Lovink, 1999). Be it the rather standard discursive 'greenwashing' of products, the more subtle creation of anger venting Net 'graffiti spaces' such as the Shell forum, or the establishment of hyperlinks to one's critics, such Net manoeuvring becomes immediately legible and trackable on the Internet knowledge maps, as we come to later in introducing new Web debate mapping

Address correspondence to: Richard Rogers, University of Amsterdam, Nieuwe Doelenstraat 16, 1012 CP Amsterdam, the Netherlands, E-mail: rogers@hum.uva.nl 


\section{Develop a Consistent Approach}

All sites are not created equal, hence, different sites require different actions.
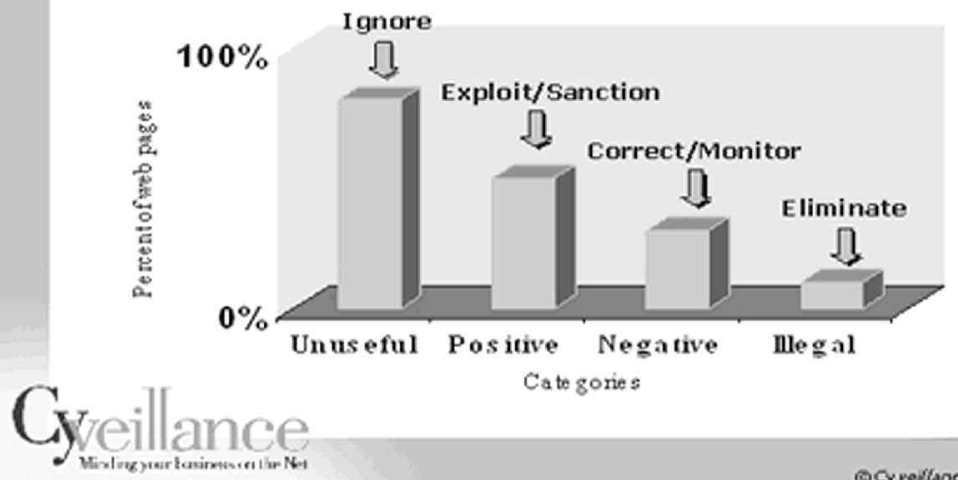

Cato gories

QCyre//anas $\cdots 1999$

Figure 1. Recommended action against rogue websites by Cyveillance. com, March 1999.

Source: cyveillance.com

techniques, based on basic 'socio-epistemological' analysis (Lubbers, 1999; Sassen, 1998; Rogers and Marres, 2000).

Especially in times of semiotic crisis (say, a spate of hearsay, followed by a drop in the company's share price), ${ }^{2}$ one may imagine intervening in the fray through an understanding of the Net manoeuvrings of multiple actors on particular issues. With discourse and link mapping in operation, the organizational manoeuvrings would assume the form of rewording websites, and linking or delinking to one's ever-changing friends and foes, supporters and debunkers. In other words, organizations would 'operate' the Internet in this new manner by reading their link and discursive positionings on knowledge maps, and nuancing their Web presence accordingly.

\section{Q THE INTERNET AS 'RUMOUR MILL'}

The Internet has been a medium of dubious repute (Dean, 1997). In the United States, where the leading monitoring firms are based, the idea of the Internet as rumour mill gained currency among leading (traditional) news organizations and beyond, with the help of a 60 


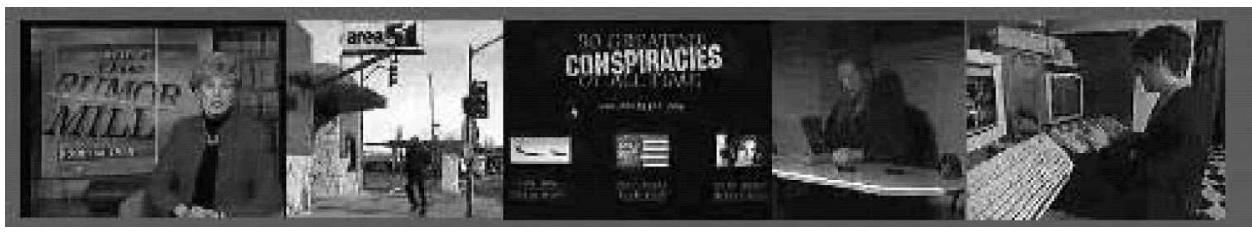

Figure 2. Opening and other clips from the 'Internet rumor mill', 60 Minutes, 1997.

Source: ewatch.com

Minutes segment, broadcast on CBS television in 1997 (see Figure 2 ). In the show the practices of both a notorious Internet rumourmonger (the conspirator with a Harvard Ph.D.) and a monitor (the seasoned Net sleuth, from a leading trade publication) were followed; it provided a picture of the amount of hearsay on the Net, the ease with which it is spread and the makings of a burgeoning industry dedicated to tracking it all down. The segment concluded with a demonstration of how unscrupulous Net operators could send messages as if they were from the 60 Minutes journalist (Diane Sawyer) or even the American president. Anything goes in this realm of information renegades and rumour raconteurs, the programme concluded.

On and off the Net, tales abounded concerning how usually reliable sources (e.g. the 'seasoned journalist') were taken in by 'word on the Net', unintentionally spreading a rumour. In the chain of Chinese whispers the word is reposted to lists and friends (in a chain letter effect), arguably living a much longer life on the global Net than it would on the local street, finding new believers in different settings, a la P.T. Barnum. The alleged downing of TWA 800 by a US Navy surface-to-air missile is one rather well-known example, also reported in the 60 Minutes segment. Another is reported by a RAND analyst, in reference to the events on the ground and on the Net during the Zapatista uprising in Chiapas, Mexico.

One short e-mail message posted in February 1995 remains particularly notorious. In it, a U.S. professor sounded a warning, reportedly telephoned to him by activists on the scene, that army troops were on the move, bombs were being dropped, and bodies were piling up in a hospital in a town near San Cristóbal. It urged the reader to spread the word, 
including by passing the e-mail on. Six months later, this highly inaccurate message was still being recirculated, appearing in discussion groups and on-line conferencing systems far removed from any specific concern with Mexico. (...) The Canadian Broadcasting Corporation (CBC) even put together a special radio program about the message and its genesis. The message was evidently written on the basis of secondhand reports and was not intended as misinformation or disinformation-but it is a good example of how that can occur anyway (Ronfeldt and Arquilla, 1998, pp. 71-72).

Internet surveillance companies have their own lists of 'Internet crisis case histories', testifying to the idea that Net rumour and innuendo is a serious matter and may cause significant damage to an organization's image and brands. The examples provided by Cybercheck, one of the Internet intelligence monitoring firms, with corporate clients, are indicative, and humorous. For example, the share price of Mrs. Field's took a fall after 'the Net' spread the rumour that the cookie company fed O.J. Simpson's acquittal party.

The ideas and tactics of the Internet surveillance companies are moving in other quarters. Mats Karlsson, World Bank vice-president for external affairs, recently called for a system 'to handle concerted email campaigns or attacks', while 'exploring ways to play a more active role on the web sites of bank critics' (Financial Times, 16 August 2001).

While surveillance companies currently publicize only corporate cases (also for the benefit of future corporate client recruitment), governments and non-governmental organizations have also been subject to rumour-mongering, rogueing and smearing. From concerned surfers Amnesty International, for example, learned of an alleged rogue site produced by a Tunisian group (www.amnestytunisia.org) with pro-governmental sympathies. The 'GINGO' site (a descriptor for a kind of NGO site) put a different face on Tunisia's human rights record, challenging and confusing Amnesty's claims. ${ }^{3}$

There are a series of techniques employed by the 'dubious' information providers. Some of the planned confusion or critical tactics ${ }^{4}$ are the results of 'domain name fudging', and organizations are advised (by Network Solutions and other domain name providers) to reserve all common suffixes,. net,. com and. org, not to 
mention the new domain suffices as. info and. biz. Greenpeace, for example, owns Greenpeace.com, as a quick search of 'whois.net' demonstrates. At Greenpeace.com a rather stern message points the surfer to Greenpeace.org.

From the 'real' organization's and the monitoring companies' points of view, the question revolves around the extent of the rogue's 'impostering'. Are they posing as the real thing? Can they thus be silenced, through off-Web legal means? On the Web, however, the question reads, do the rogues have presence within the discourse? Are they present in the same spaces as the real sources? Are these spaces reputable, i.e. are these spaces, be they search engines or other indices, endeavouring to author reputability? If so, are the rogues appearing as reputable?

In sum, cybersurveillance companies, in an effort to aid organizations in 'image-washing', supply indices (like search engine returns) of the rumours being spread on newsgroups and listserv discussions, as well as on certain self-chosen rogue websites. The client organization, taking advice from monitoring companies, proceeds by ignoring, engaging, threatening or bringing suit. An organization concerns itself with the rumour merchants on the Web itself only insofar as their critique, parody and/or polemic are well-spread or easily locatable by surfers, actively seeking the 'real' or at least reliable sources, as promised by the search engine or other Net reliability generators. Thus the main issue for organizations is the extent of the rumour merchant's position vis-à-vis the organization's own position, in a space 'authorized' by the reliability provider (see Figure 3).

\section{G GINING SENSES OF NET PRESENCE: THE HIT AND LINK ECONOMIES}

It was once thought that an organization's image and 'presence' on the Net was a product of the design of its website, and corporate marketing departments, for example, have spent large sums on a stunning Net presence, with an emphasis on information design and later Web-delivered services, such as on-line shopping with encrypted messaging for credit card and other secure information transfers. As the networked nature of the medium became more apparent, certain organizations would design their sites to keep the surfer within its 'frame'. If the surfer wished to move on via a hyperlink, 


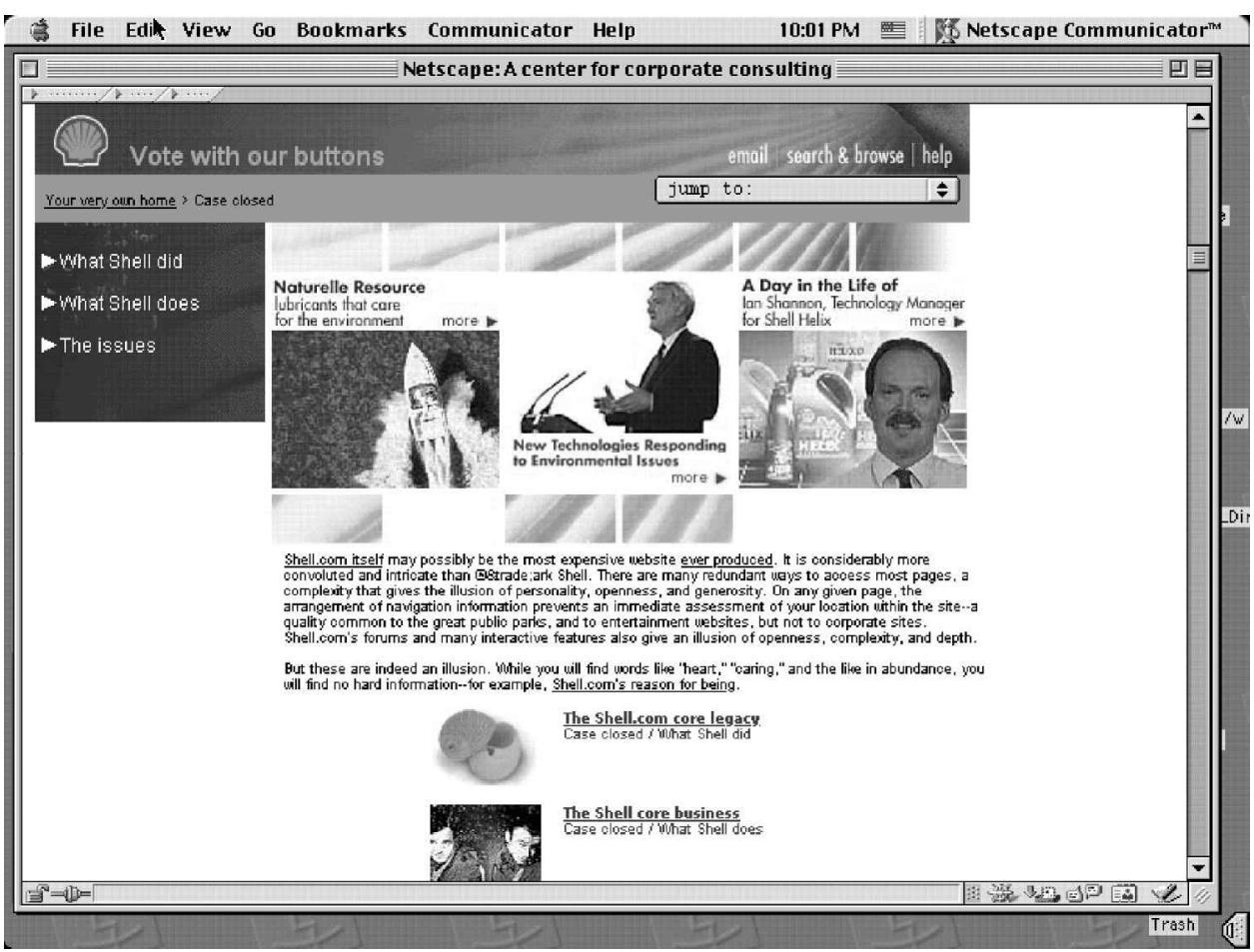

Figure 3. A rogue Shell website by ${ }^{\circledR \mathrm{TM}}$ ark.com.

Source: rtmark.com/shell.html.

he or she would remain within organization x's site, browsing through y's site in the x's frame. In another example of such '(omni-)presence' design, organizations, particularly corporations, would provide no outward hyperlinks from their sites. The surfer, it was hoped, would remain within that organization's frame of reference. With the advent of the 'Net as rumour mill', it has become increasingly clear, though, that an organization's Net presence derives from far more than site design and service delivery, and the maintenance of one's frame around the rest of the Web.

One way to think through new notions of Net presence is to understand two types of Internet economies, the 'hit economy' and the 'link economy'. For some years the Internet was run according to a 'hit economy', with advertisers and other product, service, entertainment and information providers wishing to appear on and otherwise associate themselves with the most hit sites, relative to the type of content. ${ }^{5}$ Indeed, organizations (e.g. content providers) make 
agreements with portals (e.g. entry providers such as America OnLine and Microsoft Network) to place their icons (with hyperlinks) on the opening page, thereby establishing themselves as one of the favoured points of entry on the Internet. Because of deal-making between portals and Internet browsing software, portals rank towards the top of 'hit lists', as do those which have paid for preferred placement on the opening portal pages. Recently, it was reported that there has been a winnowing of the quantity of sites visited on the Web overall, with MSNBC receiving by far the greatest share of the traffic for news portals (New York Times, 26 August 2001).

In the hit economy organizations are also making agreements with search engine companies, as the surfacing of AltaVista's 'preferred placement' service showed. As with advertising banners appearing on search engine return pages, the paid placement services boost particular sites when certain key words are entered. The services act above and beyond key word information design, HTML coding options (metatagging) and url submission, all of which together normally ensured that sites were located by engine crawlers and well-ranked by the engines. In AltaVista, clever site design and management yielded to brute payment. Despite the controversy surrounding the AltaVista spat, preferred placement is still practised (New York Times, 4 June 2001).

Whether by portal or search engine placement, preferred sites are granted a larger audience (more hits). The organizational strategy thus revolves around establishing robust portal and search engine presence. ${ }^{6}$ In all, the combination of crawler-digestible coding, key word information design and favoured placement is an organization's modus operandus in the hit economy. Robust Net presence is subsequently demonstrated on hit tables, which drives Web advertising, the seminal form of e-commerce (see Figure 4).

A second, less obvious aspect of Net presence concerns the related 'link economy'. The newer search engines place sites higher in their ranked returns if they are deemed 'authoritative sites', or sites with many 'inward links' (Gibson et al., 1998). Google operates according to this principle. Sites with larger amounts of links to them are thought to be more relevant on the Net (or, put differently, deemed more relevant by the Net). As indicated above, engineering links to one's site may involve making 'preferred placement' arrangements with portals. It may involve subscribing to a link-generator 


\section{Rank \\ Digital Media/Web Properties Visitors (000s)}

Unique

AOL Network-

1 Proprietary and WWW 47,009

2 Microsoft Sites $\quad 31,994$

3 Lycos

31,915

4 Yahoo Sites

31,272

5 Go Network

23,752

6 GeoCities

21,303

7 The Excite Network

18,861

8 Time Warner Online

13,257

9 Blue Mountain Arts

11,089

10 Amazon

10,736

Figure 4. Signs of the hit economy. Hit table by Mediametrix, March 1999. Source: mediametrix.com.

organization, such as linkexchange.com or linkpopularity.com, both of which 'guarantee' greater levels of site traffic by providing more links to the site. For the vast majority of organizations, however, it's a matter of soliciting links, for instance by expressing interest in organizing reciprocal linking. Links in may be gained through such 'hyperlink diplomacy'; they also made be granted to a site independently, either at the whim of another page-maker or as an apparent matter of another's organizational policy.

On the Web 'granting a link' (as a reference in science) and 'receiving a link' (as a citation in science) are akin to positioning oneself and being positioned by another, respectively (Wouters, 
1999). Cognisance of such positionings may lead to consideration of presence strategy. ${ }^{7}$ To whom shall the organization link? Does the organization desire to have a link from another organization? What sorts of politics of association may the linking structures around an organization imply? What may be read between the links, and by whom? In order for such considerations to have greater purchase, the status of the link must be raised beyond Webometric and search engine logic environments, which rely mainly on counting inward links (Rogers, 1996).

\section{GROM LINK ECONOMIES TO WEB EPISTEMOLOGIES}

Existing research on 'Web communities' has found that sites frequently linked to have a greater level of authority (and surfer relevance) than those receiving fewer links in. The reasoning for the 'authority', borne out in initial experimentation that eventually led to engine logics such as Google's, relates to the idea that on the whole Web-masters and page-makers make the most links to the most authentic (and thereby reputable) sources for the broad topic being searched. In the example given in one particular piece of empirical research, the topic 'Harvard' returned some 800,000 pages in standard search engines, with www.harvard.edu not appearing in the first set of 10 (Gibson et al., 1998). With a 'hyperlink-induced topic search', which takes into account 'links in' and the pointer text, the college's main site appeared first, with commentaries on Harvard or other uses of the word dropping to lower rankings. Harvard.edu has the most links in from pages where the word Harvard appears. In the returns the main site was followed by www.hbs.harvard.edu, www. law.harvard.edu and ksgWeb.harvard.edu (see Figure 5).

Thus search engines operating with such link authority measures-such as Google-could induce movement away from a pure hit economy to a link-and-hit economy, at least for those surfers preferring search engines as their entry point to the Web. The sites with the most links in would show highest on the rankings. Presumably they then would be hit more frequently.

The demonstrable value of link-related logics for establishing topic source authority provides some way towards grappling with the 'rumour mill', as far as basic Web epistemology is concerned. Indeed separating the wheat from the chaff has long been the key issue for 
Data for www.shell.com

Contact Info

$$
\begin{aligned}
& \text { Shell Dil Company } \\
& \text { P.0. Box 20329 } \\
& \text { Houston, TK } \\
& 77225 \\
& \text { hes \& Dinections } \\
& \text { Houston City Guide } \\
& \text { Dnline: 7i15, }
\end{aligned}
$$

\section{site stats}

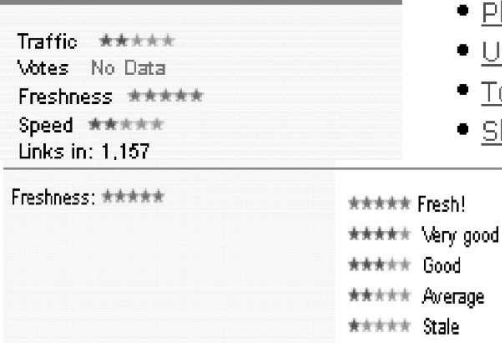

\section{Related Links}

- Texaco Online (wwwtexaco,com/)

- Mobil Corporation (wwimobil.com/)

- The World of Chevron (www,cheuron,com/)

- New Bp Amoco Web Site (www.bp,como)

- New Ba Amaco Web Site (www.amaco.com/)

- Exxan Corporation, Oili Usa. (www.exnon.com/)

- Phillips Petroleum Company (www.phillips66.com/)

- Unocal Corporation - A New Breed of Energu Company

- Total: Total on The World Wide Web (wnin.total.como)

- Slb (ww.slb.com/)

Figure 5. Signs of the link economy. The Alexa tool bar, with individual site stats, including related links, and links in 'as an indication of reputability'. Source: alexa.com.

both engines (ranking) and surfers (searching), desiring to find the 'real' source. The 'chaos' of the Internet (to use the vernacular) may be viewed as a product of the lack of source authority, in an information free-for-all brought about by 800,000 pages with something to say about Harvard, all being listed by engines, returning sites with frequent Harvard key words and Harvard metatags (cf. Rogers, 1998). Engines with link authority logics, where www.harvard.edu rises to the top of the returns, author a new form of basic Web epistemology (Waltz, 1998). That is, they provide an indication of the status of information according to measurable reputability dynamics given by the Web.

In yielding greater 'real' source reliability, where an institution is queried, search engines using link authority logics thereby also would remedy rogueing, and, from the real source's perspective, the potential epistemological crisis resulting from surfers' consulting the rogue site over the source site. In the case of epistemological competition 
(the imposter versus the real), link authority points to shell.com as opposed to the imitation site by an art group (see Figure 3), and to amnesty.org as opposed to amnesty-tunisia.org. The rogues have less authority, for they have been granted fewer links in, with the link pointer text 'amnesty'.

Whenever the query relates not to an institution but to an issue, epistemological competition becomes even greater. Taking an example from our research, well over one million pages have something to say about 'climate change'. Since there is no such thing as the 'real climate change site', the challenge concerns locating and querying not the one real source but the 'discourse'. Here the issue revolves around using organizational linking logics in order to reliably author the discourse, and be able to query it for positionings and positions in a debate. In a variation on the English parliamentary expression, where you stand depends on where you're positioned.

\section{GROM WEB EPISTEMOLOGIES TO WEB DISCOURSES: GOVCOM.ORG}

Before explaining the kind of (epistemological) thinking behind Web discourse, it is instructive to introduce a broad distinction about the Internet that arises from the two types of searches mentioned above, i.e. a search for an institution or for a subject matter. Seeking the one source (i.e. the real Harvard) may be said to carry with it the idea that the Web is made up of single sources. In this view, the Web becomes a series of brochures, catalogues, market stalls, or kiosks of individual organizations. Each kiosk authors and provides information about itself.

The Web, however, may be more readily conceived of as a hypertext, or, adding images, videos and sounds, a hypermedia environment, where conventional notions of both information provision and authorship are challenged. ${ }^{8}$ For our purposes the Web is thought of not as a series of information spaces authored by single sources but as discourse spaces to be authored by surfers (in the case of hypertext theory) or, in this case, to be authored by cartographic techniques and tools.

Just as link authority engines now author the reputable source (the real Harvard) and filter out the rogues, logics may be conceived to author a discourse. Moving from a source to a discourse perspec- 
tive, Web pages are viewed as a series of inputs into discourses to be queried for standpoints within discourses across sites. Those sites (and viewpoints) not recognized as relevant by the discourse would be filtered as if hearsay.

Moving away from the basic epistemology of real source ('fact') and imposter ('fiction'), the epistemological notion sought here concerns positioning presence. Are the organization and organization's own points of view present in the Web discourse? Has the network making up the discourse granted that organization and that point of view presence?

Govcom.org is a conceptual url indicating three leading discursive source types on the Web and the three leading protagonist types in contemporary societal debates. (More a 'support act',. edu or. ac is thought of as being incorporated in the viewpoints and positionings of the. govs,. coms and. orgs.) The conceptual url follows from projects to map the climate change and genetically modified food debates on the World Wide Web. ${ }^{9}$ Like the 'Harvard.edu' researchers, here the project began with the observation that search engine returns (in the hit economy) provide little in the way of knowledgeable relevance and reputability ranking. When faced with a long list of sites containing the key word 'climate change' or 'gm food', it is difficult to gauge the status and relevance of each of the organization's 'knowledge' and 'position' vis-à-vis other organizations, apart from the fact that they are 'on the list'. Which of the organizations are key players in the debate? Whom to trust? How can one tell?

When faced with such a list, the knowledge surfer is liable to begin with an organization s/he already trusts (the reputable source, as Harvard.edu). In order to gain a picture of the issue, one is apt to follow the outward links from one trustworthy source to other sources deemed relevant (through the hyperlinks) by one's initial reputable site. If, however, one encounters a site without any outward links from its climate change page (as a corporation without outward links, employing the style of 'Net omnipresence'), the surfer may backtrack and follow another route, or one may very well 'lose track'.

Here the experience of purposive mall shopping is analogous to Web knowledge surfing. After a period of 'on-the-ball' browsing, one is likely to lose track of the original purpose. Lulled by the diversions 
of the Net (as by those in the mall), most everything becomes of mild interest until that time when one regains a sense of purpose.

Knowledge or discourse maps, plotted on the basis of trustworthy inter-organizational hyperlinking patterns, provide a way out of the information daze. A potential 'knowledge surfer's course' may be made visible by mapping the discourse and a number of routes through the reputable links the surfer may wish to follow (Marres and Rogers, 1999; Rogers and Zelman, 2001). So instead of mapping individual site structure to gain a sense of depth, as many artistic (WebStalker) and commercially available products (Inxight on AltaVista's Discovery) do, here a set of sites is mapped through hyperlinks to gain a sense of the breadth of a discourse. ${ }^{10}$ The links out of a group of initial reputable sources, involved in a debate such as climate change, are taken as the population, and those interlinking sufficiently within the population constitute the sample of the network. ${ }^{11}$ The connections (or links) between organizations are mapped, and routes are thereby found through the network.

The 'socio-epistemological' logic behind the mappings and the routings has to do with reputation and knowledge networks. Interorganizational hyperlinkings provide a semblance of a knowledge and reputation network between organizations. Somewhat akin to a footnote in a manuscript, a hyperlink is thought of here as an acknowledgement by one organization of another organization's relevance to the discourse, based on some appreciation for that latter organization's knowledge and reputation. A link indicates 'belonging'. Depending on the size of the population (of organizations), multiple acknowledgements of relevance through hyperlinking determine the sample. Once hyperlinks are taken to be acknowledgements of relevance to a discourse, the network maps may be thought to reveal one or more discourses, within which debates are taking place. The spread of govcom.org (or. govs,. coms and. orgs) within the discourse is a sign of (transdiscursive) 'debate'.

Thus in govcom.org, the Web is conceived of as a series of discourse or debate spaces awaiting mapping, and routing instructions. Organizations' linkings provide the potential routes to be taken; routes through the discourse may be conceived of as storylines. Both the authoring and the authorizing entity are the network, not the surfer (cf. Landow, 1997).

Where an organization is positioned in such a discourse (and on 
a discourse map) thus becomes a matter of organizational concern. For example, is it central, peripheral or absent? From the discourse's perspective, is it relevant? Does an organization's point of view matter if it is absent from the discourse map?

In sum, unlike the hit, and hit-and-link, economy search engines, which respectively find pages on the basis of each site's tagging and key word placements, or on the basis of quantitative reputability measures, govcom.org rethinks the search engine as a debate landscaping device, providing discursive authority logics (who's in, who's

MOTHERMAP

undirected/all
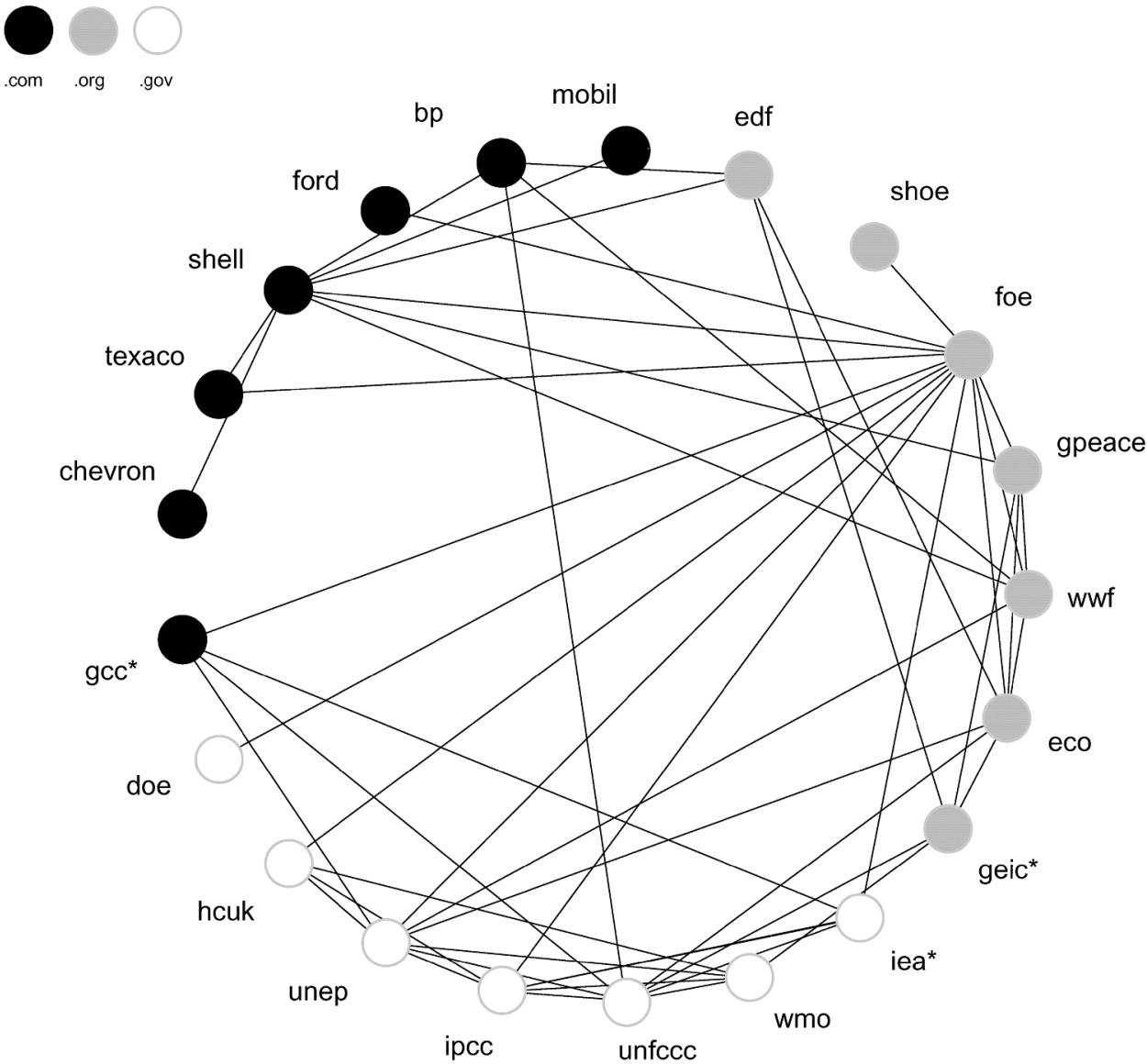

Figure 6. Organisational linking patterns (and potential routes) in the climate change discourse on the Web, November 1998. See Appendix for legend. Map by Noortje Marres and Alex Bruce Wilkie. 
out), inter-organizational routing instructions (see Figure 6) and indications of levels of transdiscursive debate. Starting from a cluster of trusted sites dealing with an issue, the technique maps the linking logics of organizations to demarcate the discourse and to determine potential stories within it. ${ }^{12}$

\section{CONCLUSION: FROM PRESENCE TO 'BUBBLE' OPERATION}

A history of web presence strategizing, as I have outlined above, begins with the recognition by firms and others of the impacts the Internet rumour mill may have on share prices and brand recognition. In the mid- to late-1990s, Internet surveillance companies stepped in, offering services to chart 'word on the Net', and recommend tactical action to be taken against impostors and critics, influencing reputation.

With the transition from the hit economy to the link economy, in the late 1990s, it was recognized, at the same time, that an organization's Web reputation no longer derives from its site design. Rather, it is a product of the organization's showing in reputable spaces.

Indeed, attempts are often made to buy presence in spaces where source reputability is authored. These spaces include directories, portals and search engine returns. For example, Shell's viewpoints on its own sensitive issues have appeared as advertisement banners on AltaVista whenever 'Greenpeace', 'sustainable development' and other environmentalist terms are entered into the engine or returned in the first set of 10 (see Figure 7). ${ }^{13}$

In the research described above, new means have been developed to author reputable space - the issue network - and understand presence and debate in it. The research takes advantage of insights and techniques from such reputation-makers in the link economy as Google, and moves beyond them. If hyperlinks are understood as

\section{see how we plan to make the world even greener}

Figure 7. A portion of the Shell 'splash' appearing in AltaVista when 'Greenpeace' is queried or returned in the first set of 10 August 1999. Source: via altavista.com 
source recommendations per issue area, techniques may be developed to find and chart issue networks. These maps show the relevant sources per issue, and also what each is saying about the issue. The organizations outside the issue network are filtered out.

From the point of view of socio-epistemological discursive mapping, organizational Net presence derives from overall 'positioning', that is, with whom an organization is linked (inwards and outwards) and thus associated (see Figure 6), as well as where it stands on the issue once they are queried for substantive position [see Figures 8(a) and (b)].

Where climate change is concerned, a topic queried from the link maps could be 'developing countries', and the mapped organizations' stances on this subissue may be depicted on discursive maps. ${ }^{14}$ One notes that in the 'developing countries' map, corporations provide little input to the 'story' on 'developing countries and climate change'. Only the corporate lobby group (Global Climate Coalition or GCC) has chosen to take a stand on developing countries. In the 'uncertainty and climate change' discourse map, the NGOs provide scant input, preferring not to engage in the debate about the 'uncertain' science of climate change.

Discursive maps are thought of as generally useful tools for thought, providing one understanding of particular organizational relationships, that is, inter-organizational relevance and reputability acknowledgements on the basis of hyperlinks. The relevance logics demarcate discursive networks, and govcom.org queries show whether there are 'great debates' ongoing, in the making or entirely absent.

Govcom.org also asks, does the discourse exhibit transdiscursivity? Are organizations acknowledging and deeming relevant players outside their immediate 'domain' of understanding? Where on the Web do we find the elusive neo-pluralist potential, where there is not only cross-domain acknowledgement but transdiscursive viewpoint engagement? In the climate change debate, we do have multiple domains present, and we have found the makings of debate around the principle knowledge claim of the Intergovernmental Panel on Climate Change, 'the balance of evidence suggests a discernible human influence on global climate' (Rogers, 1998). But here our discourse maps reveal only modest open debate on the subissues. 


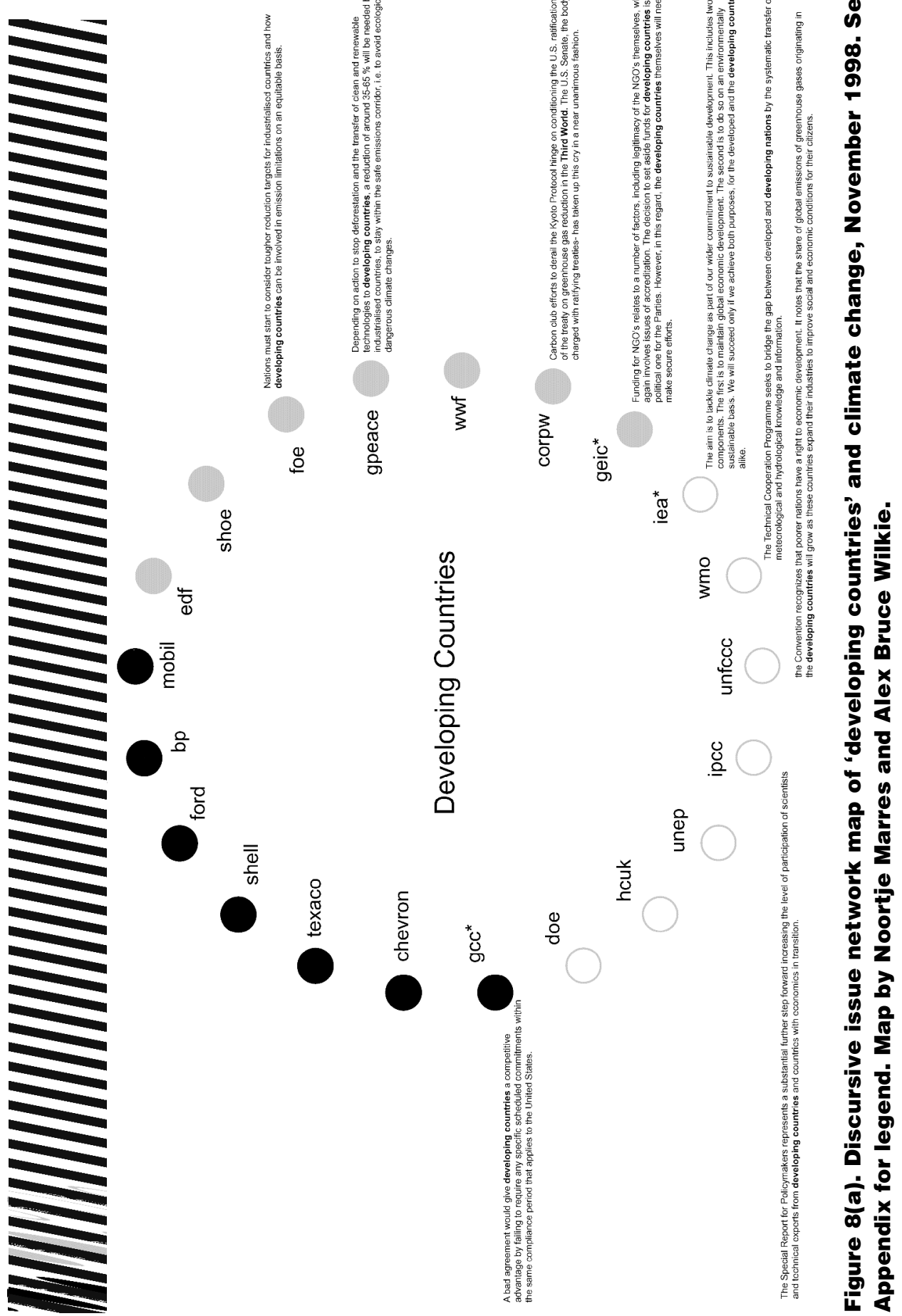




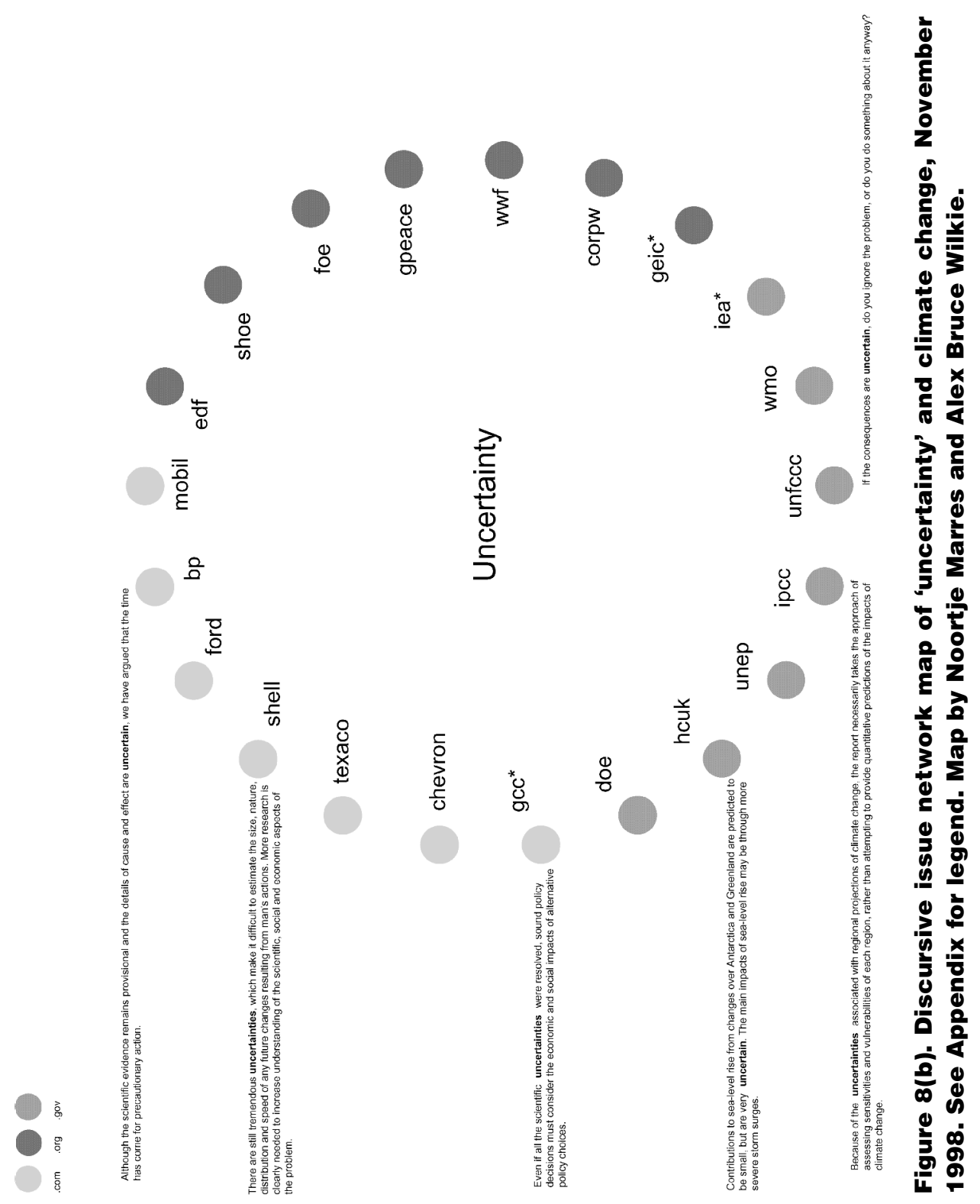


As has been argued, the maps also provide potential knowledge surfer routes through complex discourses. The maps thereby potentially author storylines, as we noted with developing countries and uncertainty. In all, the maps author a social epistemology in the sense that they provide ways of coming to know about climate change using issue networks, not individual websites, as 'the source'.

Once at least the kind of thinking behind the govcom.org mapmaking and map-reading become apparent to the organizations on the maps, they may well find themselves in need of newfangled Web operators. I have dubbed these newfangled analysts 'bubble operators'.

The bubble is a term borrowed from US Navy command and control centre operation, as on a battleship; it also has been applied to the expert operation of other critical systems, such as nuclear power plants and air traffic control. It similarly may apply to newsgathering or to computerized stock trading environments. Two quotations provide an introduction to the notion of the bubble, or more specifically, 'having the bubble'.

The bubble is a not a metaphor for the cognitive map or representation; rather 'having the bubble' expresses the state of being in control of one.

To declare publicly that you have 'lost the bubble' is an action that is deemed praiseworthy in the Navy because of the potential cost of trying to fake it. Depending upon the situation, either one or more of the other people in the center will feel they have enough of the bubble to step in, or everyone will scramble to try to hold the image together by piecemeal contributions. As a rule, even a few minutes of relief will allow the original officer to reconstruct the bubble and continue (Rochlin, 1997, p. 240).

The term 'having the bubble' conveys the cognitive management of numerous information streams and instrument readings in situ. One maintains the image of the complex information landscape, and continually translates one's understanding of the situation into communication outputs. The operator mentally maps the information and dynamically interacts with a system increasingly of his own (cognitive) making. 
Employing govcom.org logics and representing interorganizational linking and discursive relationships on maps, one may track an organization's 'showing' on particular issues and thereby understand its Net presence. Subsequently, operators-'having the bubble'-would take real-time decisions to re-word the website, link or delink, in order to nuance that presence.

\section{NOTES}

1. A brief overview of the celebrated cases of Internet trademark infringement and slander (e.g. McDonald's, Colgate Palmolive, Scientology, etc.) is available, among other places, on a Wayne State Law School site, www.law.wayne.edu/ litman/classes/tm/trademark.htm.

2. The major Internet monitoring firms advertise their services by pointing to celebrated cases of Net rumour-mongering followed by a drop in a company's share price.

3. At the behest of the Tunisian government the site was moved to www.rightstunisia.org in March of 1999. Here it is worth noting that the. org site seemed to represent a government-organized NGO (GONGO) or government-inspired NGO (GINGO) as opposed to a more conventional (grassroots) NGO. The distinction is noted in Ronfeldt and Arquilla (1998).

4. The position towards 'rogue website as form of social criticism' is taken up, among other places, in articles in the Ottawa Citizen and the Montreal Gazette, 6 September 1997.

5. The hit economy is mitigated by reputation issues. Association with the most hit pornographic sites, for example, may not be deemed desirable. For example, Cyveillance, the Internet monitoring firm, issued a press release in early 1999 entitled, 'America's leading brands link to porn', urging Internet monitoring and surveillance of the practices of dubious information and entertainment providers. See http://www.cyveillance.com.

6. For an idea of the types of services provided in the hit economy, see http://www.polepositionWeb.com/; http://www.ruranked.com/reports.htm; and http://www.filehouse.com/rankhigher/.

7. In their tenth Internet usage survey, conducted by Georgia Tech's Graphic, Visualization, \& Usability Center, $62 \%$ of the Webmasters queried indicated that they (strongly or somewhat) agreed with the statement, 'The sites I am responsible for have a strategy for linking to other sites'. The survey may be found at http://www.gvu.gatech.edu/user_surveys/survey-1998-10/. The question concerning 'strategic linking', the first of its kind in the survey series, is found at http:/www.gvu.gatech.edu/user_surveys/survey-1998-10/graphs/Webmaster/ q51.htm.

8. In a hypermedia environment, the surfer (or reader) is sometimes said to 'author' the discourse in the sense that $\mathrm{s} /$ he determines her/his own path or route 
through the information, thereby making her/his own 'story'. On author/reader inversion in hypertext environments, see Levinson (1997).

9. The work has been performed at the Jan van Eyck Akademie, Maastricht, 1999-2000, with an archive available at http://www.govcom.org.

10. WebStalker is available at http://www.iod.org/Webstalker. For an overview of website and other Internet mapping techniques and projects, see http://www. cybergeography.org.

11. As a starting point to map a debate or discourse, one chooses a set of organizations thought to be relevant to the debate. For climate change, these could be Friends of the Earth, Shell and the UN (IPCC). In order to make a socioepistemological map from linking patterns, one needs to discern the links into the sites, and the links out. AltaVista has a number of 'fancy' search features where one can learn of a site's referral logs (or links in). With 'climate change' AND link:www.shell.com, one may retrieve the urls of all organizations, saying something about climate change, linked to Shell. One may refine the search to only those '.orgs', only those '.coms', or some combination of domain types, linking to Shell. Thus AltaVista's 'fancy' boolean syntaxes lays the groundwork for link mapping. (Links out may be determined from site HTML stripping software.) Using Discovery's crawling and indexing features, one may define a 'search space' (or 'discourse space') and have a set of sites queried and returned to one's desktop. The tool is asked to return the 'links to' these sites on a regular basis, i.e. to find and return the 'fresh links'. Factoring in freshness, for links as well as text, may be important in times of semiotic crisis.

12. Once a set of central organizations has been determined (see previous note), one demarcates the discourse by employing centre-periphery logics, e.g. organizations are included in the discourse if two or more central players link to them. 13. The 'greenpeace' queries on AltaVista that generated Shell sensitive issue advertising banners (and 'splashes') were performed in early August 1999. See also govcom.org (1999).

14. The organizations' positions on 'developing countries' within the climate change debate were gained through the use of key word in context (KWIC) Web page queries, using the textual computing analysis tool (TACT), available at http://tactWeb.humanities.mcmaster.ca. The empirical work was performed by Noortje Marres.

\section{$\square$ REFERENCES}

Dean, J. (1997) 'Virtually citizens', Constellations, 4(2): 264-282.

Garcia, D. and Lovink, G. (1999) N5M3, Next Five Minutes 3 Workbook. Amsterdam: Society for Old and New Media.

Gibson, D., Kleinberg, J. and Raghavan, P. (1998) 'Inferring Web communities from link topology', in Proceedings of the 9th ACM Conference on Hypertext. Pittsburgh: ACM.

Govcom.org (1999/2000) The Rogue and the Rogued: Amongst the Web Tacticians, film. Maastricht: Jan van Eyck Akademie. 
Landow, G. (1997) Hypertext 2.0. Baltimore: Johns Hopkins.

Levinson, P. (1997) The Soft Edge: A Natural History and Future of the Information Revolution. London: Routledge.

Lubbers, E. (1999) 'The Brent Spar syndrome', in G. Lovink et al. (Eds), Read $M e$. New York: Autonomedia.

Marres, N. and Rogers, R. (1999) 'To trace or to rub? Screening the Web navigation debate', Mediamatic, 9(10), 4(1): 117-120.

Rochlin, G. (1986) "High-reliability" organizations and technical change: some ethical problems and dilemmas', IEEE Technology and Society Magazine, 9(3): 3-9.

Rochlin, G. (1997) Trapped in the Net. Princeton, NJ: Princeton University Press.

Rogers, R. (1996) 'The future of science and technology studies on the Web', EASST Review, 15(2): 25-27.

Rogers, R. (1998) 'Playing with search engines and turning lowly information into knowledge', Mediamatic, 9(2/3): 122-130.

Rogers, R. and Marres, N. (2000) 'Landscaping climate change: a Web mapping technique for understanding science and technology debates on the World Wide Web', Public Understanding of Science, 9(2): 141-163.

Rogers, R. and Zelman, A. (2002) 'Surfing for knowledge in the information society', in G. Elmer (Ed.), Critical Perspectives on the Internet. Lanham, MD: Littlefield \& Rowman.

Ronfeldt, D. and Arquilla, J. (1998) The Zapatista Social Netwar in Mexico. Santa Monica: RAND.

Sassen, S. (1998) Globalization and its Discontents. New York: New Press.

Waltz, E. (1998) Information Warfare: Principles and Operations. Boston: Artech House.

Wouters, P. (1999) Citation Culture. Ph.D., Science \& Technology Dynamics, University of Amsterdam.

$A P P E N D I X: L E G E N D$

.org (Non-Governmental Organizations):

1. Gpeace

2. FoE

3. WWF

4. ECO

5. EDF

6. Shoe
Greenpeace

http://www.greenpeace.org/ climate

Friends of the Earth

http://www.foe.co.uk/climatechange/

World Wildlife Fund

http://www.panda.org/climate/

ECO Climate Action News Network

http://www.igc.apc.org/climate/Eco.html

Environmental Defense Fund

http://www.edf.org/issues/GlobalWarming.html

Shoeworld's On-line Petition lobbying Nike

http:/www.shoeworld.co.uk/protest/ 
.com (Corporations):

1. Shell

2. Mobil

3. $\mathrm{BP}$

4. Texaco

5. Ford

6. Chevron
Royal Dutch/Shell Company

http://www.shell.com/c/c2_01.html

Mobil Oil

http://www.mobil.com

British Petroleum

http://www.bp.com

Texaco

http://www.texaco.com/default.htm

Ford Motor Company

http://www2.ford.com/environment/enviroindex.html

Chevron

http://www.chevron.com/environment/peopledo/index.html

.gov (Governmental Organizations):

1. IPCC

Intergovernmental Panel on Climate Change

http://www.ipcc.ch

2. UNFCCC United Nations Framework for the Climate Change Convention

http://www.unfccc.de/

3. UNEP

United Nations Environmental Programme

http://www.unep.ch/index.html

4. WMO

World Meteorological Organisation

http://www.wmo.ch

5. DoE

Department of the Environment (United Kingdom)

http://www.detr.gov.uk/detrhome.htm

6. HCuk

The Hadley Centre

http://www.meto.govt.uk/sec5/CR_div/Brochure

.org (Delegate Organizations):

1. IEA

2. GCC

3. GEIC
International Energy Agency

http://www.iea.org/climat.htm

Global Climate Coalition

http://www.globalclimate.org

Global Environment Information Center

http://www.geic.or.jp/geic-climate.html 